\title{
Bi- tri- and few-layer graphene growth by PLD technique using $\mathrm{Ni}$ as catalyst
}

\author{
Umber Kalsoom*, M. Shahid Rafique, Shamaila Shahzadi, Khizra Fatima, \\ RABIA SHAHEEN
}

Department of Physics, University of Engineering and Technology, Lahore-54890, Pakistan

\begin{abstract}
The objective of the present research work is to optimize the growth conditions of bi- tri- and few-layer graphene using pulsed laser deposition (PLD) technique. The graphene was grown on n-type silicon $\left(\begin{array}{lll}1 & 0 & 0\end{array}\right)$ at $530{ }^{\circ} \mathrm{C}$. Raman spectroscopy of the grown films revealed that the growth of low defect tri-layer graphene depended upon $\mathrm{Ni}$ content and uniformity of the Ni film. The line profile analysis of the AFM micrographs of the films also confirmed the formation of bi- tri- and a few-layer graphene. The deposited uniform Ni film matrix and carbon/Ni thickness ratio are the controlling factors for the growth of bitri- or few- layer graphene using pulsed laser deposition technique.
\end{abstract}

Keywords: graphene; Raman spectroscopy; atomic force microscopy; pulsed laser deposition

\section{Introduction}

Graphene is being investigated as a building block of graphite since 1940s [1]. In 2004, Novoselov successfully identified graphene layers and its discovery in 2004 completed the carbon family [2]. It is a two-dimensional building block of carbon allotropes and can be stacked into 3D graphite, rolled into 1D nanotube CNT, or wrapped into $0 \mathrm{D}$ fullerenes $[1,3]$. Variety of different carbon related crystalline and non-crystalline structures may exist in different $\mathrm{sp}^{2}$ and $\mathrm{sp}^{3}$ hybridization states [4]. Graphene exhibits unique electronic properties, for instant, high charge carrier mobility and quantum Hall effect [5]. Utilization of all these properties is based on the availability of fine and controllable fabrication technique.

Initially, graphene was formed by micromechanical cleavage [2]. Metals like nickel, platinum and cobalt have also been used in the synthesis of graphene [6-8]. Graphene prepared on a metal substrate possesses more uniform layers due to dissolution and precipitation of carbon in metal $[9,10]$. The number of graphene layers depends on how

*E-mail: umber.uet@gmail.com much carbon atoms segregate from the carbonmetal solid solution $[11,12]$. The lattice constants of $\mathrm{Si}, \mathrm{Ni}$ and $\mathrm{C}$ are $0.543 \mathrm{~nm}, 0.352 \mathrm{~nm}$ and $0.332 \mathrm{~nm}$, respectively. A smaller lattice mismatch between $\mathrm{Ni}$ and $\mathrm{C}$ provides better opportunity to grow graphene layers. Graphene can be grown using several techniques such as micromechanical cleavage [2], thermal decomposition [13] and metal induced graphitization $[14,15]$ graphite oxide reduction [16], molecular beam epitaxy (MBE) [17], chemical vapor deposition (CVD) [18] and pulsed laser deposition (PLD) [19, 20].

Among these, PLD is well-known to produce graphene from multilayer to few layers [21]. Therefore, it is expected to promote carbon adatom diffusion into Ni film at low substrate temperature. In addition, the thickness ratio of $\mathrm{Ni}$ to graphite film can be controlled easily in PLD by varying the number of laser shots on $\mathrm{Ni}$ and graphite. Keeping in mind these aspects, controllable growth of graphene can be obtained by PLD technique [22]. In this research work, Ni based bi- tri- and fewlayer graphene has been grown on Si substrate using PLD technique. 


\section{Experimental}

In this experiment, bi- tri- and few-layer graphene have been deposited using nickelgraphite (Ni-C) target on $\mathrm{n}^{+}$silicon $\left(\begin{array}{lll}1 & 0 & 0\end{array}\right)$ substrate. $\mathrm{Ni}$ was used as a catalyst. The target Ni-C was prepared by embedding $\mathrm{Ni}$ disc of $\sim 2 \mathrm{~cm}$ diameter into the graphite disc of $\sim 5.7 \mathrm{~cm}$ in diameter. A schematic of the Ni-C target is shown in Fig. 1a. The target was mounted on a target holder fitted with a rotatory motor as well as a translatory motorized stage. The rotatory motor rotated the target during the deposition and the translatory motor brought either graphite or $\mathrm{Ni}$ in front of the laser beam. Si substrate was placed in parallel to the multicomponent target at a distance of $1.6 \mathrm{~cm}$.

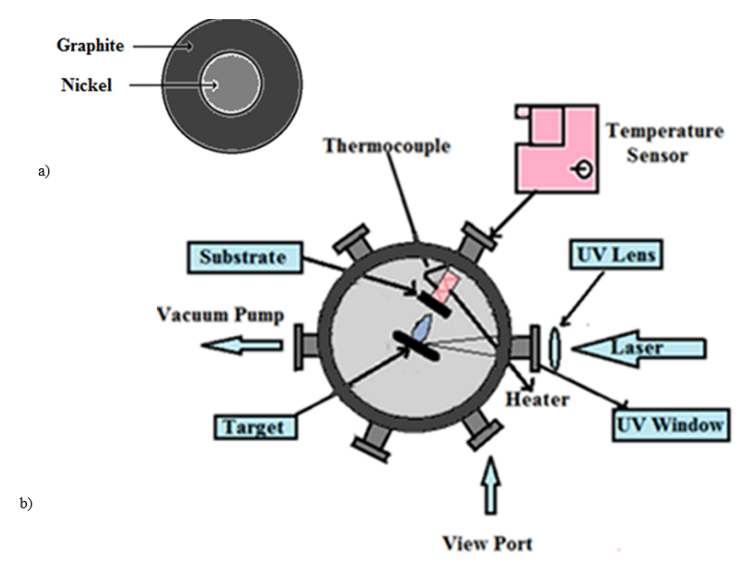

Fig. 1. (a) schematic Ni and graphite disc used as a target, (b) schematic of experimental setup.

Schematic of the experimental setup is shown in Fig. 1b. A KrF excimer laser $(248 \mathrm{~nm}, 20 \mathrm{~mJ}$, $20 \mathrm{~Hz}$ ), placed at an angle $45^{\circ}$ to the target surface was used to ablate the target. The experiment was carried out in a stainless steel chamber evacuated to a pressure of $1.33 \times 10^{-3} \mathrm{~Pa}$ by rotary and turbomolecular pumps.

To deposit the graphene films, Ni was deposited at the first step. Immediately after the $\mathrm{Ni}$ deposition, the substrate temperature was raised to $530{ }^{\circ} \mathrm{C}$ in order to enlarge the average grain size of $\mathrm{Ni}$ film. Afterwards, graphite was deposited on the $\mathrm{Ni}$ layer. The deposited films were allowed to cool down naturally at room temperature under vacuum. Graphene thin films were fabricated by varying the number of laser shots on Ni part of the target and the number of laser shots on graphite part was kept constant. Five films were deposited under the scheme listed in Table 1.

For the structural analysis, all the as-deposited films were analyzed by HORIBA Jobin Yvon LabRAM HP Raman spectrometer using $632.8 \mathrm{~nm}$ laser as the excitation source. Atomic Force Microscopy (AFM) Veeco was used to evaluate the thickness and the number of graphene layers.

\section{Results and discussion}

\subsection{Raman analysis}

Raman spectroscopy is the most reliable, nondestructive and quick inspection method to get information of graphene and carbon related structures [4]. Fig. 2 shows Raman spectra of films grown at different $\mathrm{Ni}$ concentrations (different number of laser shots on nickel) keeping graphite concentration (number of laser shots on graphite) constant. The spectra exhibit three remarkable peaks (for all Ni concentrations) observed at 1330, 1590 and $2670 \mathrm{~cm}^{-1}$. The Raman peak appearing at $1330 \mathrm{~cm}^{-1}$ is referred to as D band. D band originates due to defected graphite and is usually called disorder-induced D band. It is associated with the breathing mode of $\mathrm{sp}^{2}$ aromatic rings. $\mathrm{D}$ band is energy dispersive and a slight shift in its position (if there is any) might depend on the change in the excitation energy [23]. The second prominent Raman peak appearing at $1590 \mathrm{~cm}^{-1}$ is referred to as $\mathrm{G}$ band [4]. G band represents the crystalline quality and is an evidence for the formation of hexagonal lattice in graphite. It is due to the $\mathrm{sp}^{2}$ bond stretching of all pairs of carbon atoms. Single line appearing at $1580 \mathrm{~cm}^{-1}$ for monocrystalline graphite is highly symmetric [24].

The third prominent peak appears at $2670 \mathrm{~cm}^{-1}$ and is referred to as $2 \mathrm{D}$ peak/band. 2D band is the graphite like $\mathrm{G}$ band, which is a double resonance of D band [25].

In the case of Ni-7500 (Fig. 2e), an additional shoulder peak appears at $1610 \mathrm{~cm}^{-1}$ which 
Table 1. Film deposition scheme.

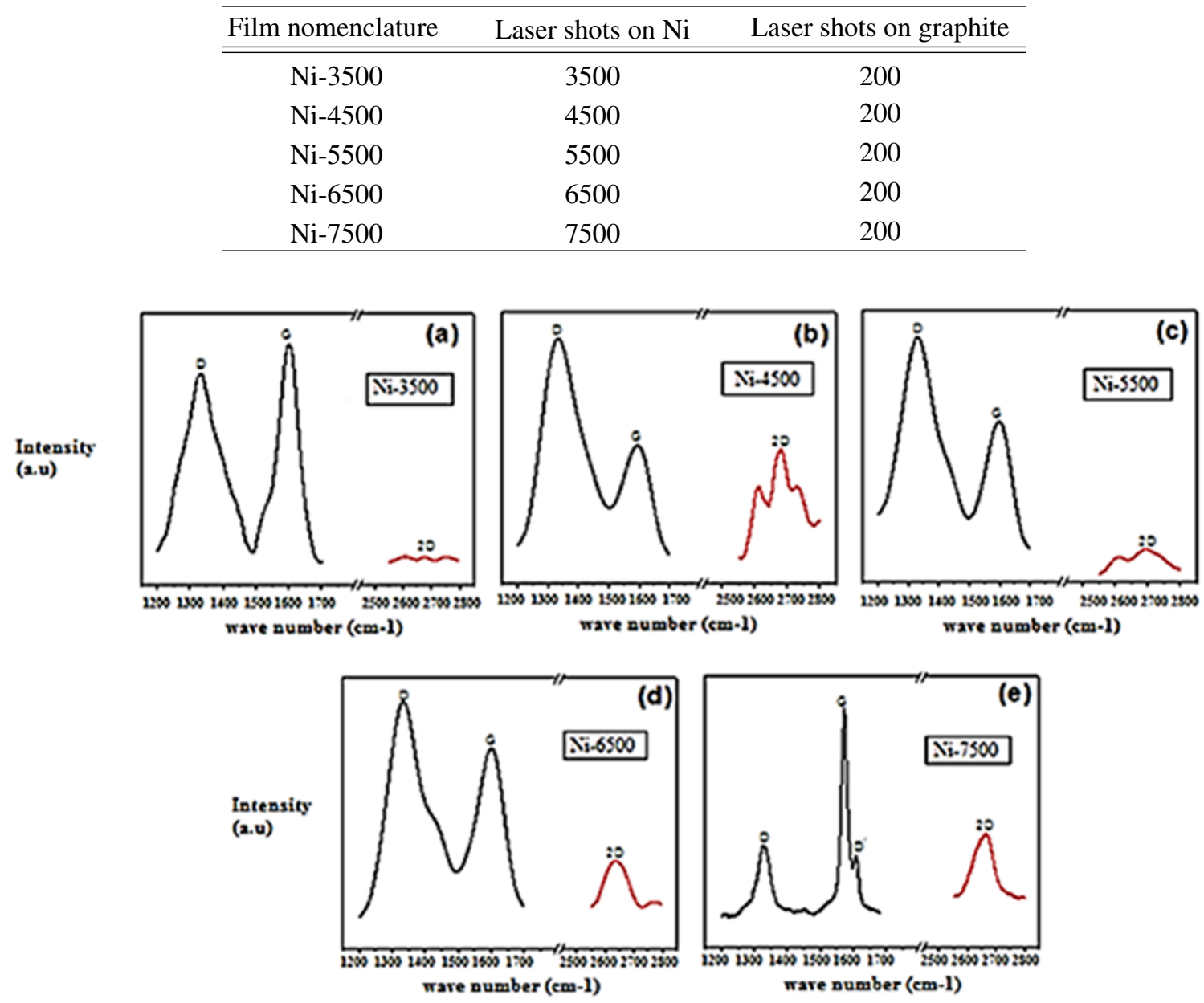

Fig. 2. Raman spectra of graphene prepared with different Ni concentrations which were varied by taking (a) Ni-3500, (b) Ni-4500, (c) Ni-5500, (d) Ni-6500 and (e) Ni-7500.

is referred to as $\mathrm{D}^{\prime}$ peak (defected graphite). $\mathrm{D}$ and $\mathrm{D}^{\prime}$ bands are indicative of defected graphite [23].

The main difference between the Raman spectra of graphene and graphite depends on the change in intensity, position and shape of 2D peak. 2D band can be used for determination of a number of graphene layers [25]. $\mathrm{G}$ and $2 \mathrm{D}$ bands position, width and shape can be changed by increasing the number of graphene layers [26]. The 2D band shown in Fig. 2(a-c) is splitted into two or three components which is due to armchair and zigzag orientation of the carbon atom sheet with respect to the strain axis [27].
The ratio $\mathrm{I}_{\mathrm{D}} / \mathrm{I}_{\mathrm{G}}$ is used as a measure for non-sp $\mathrm{s}^{2}$ to $\mathrm{sp}^{2}$ bonding and depends on the concentration of electrons. $\mathrm{I}_{2 \mathrm{D}} / \mathrm{I}_{\mathrm{G}}$ ratio is used to investigate the number of graphene layers. The intensities of $I_{D}$, $\mathrm{I}_{\mathrm{G}}, \mathrm{I}_{2 \mathrm{D}}$ and calculated ratios are given in Table 2.

An increase in $\mathrm{I}_{\mathrm{D}} / \mathrm{I}_{\mathrm{G}}$ ratio in the Raman spectra of the films Ni-3500 and Ni-4500 shown in Fig. 2a and Fig. $2 b$ indicates an increase in defects due to the large number of graphene layers. For Fig. 2(ce), it is noticed that the intensity ratio of $I_{D} / I_{G}$ appears to decrease with increasing laser shots on $\mathrm{Ni}$ target. Moreover, the Raman profile for Ni-7500 showing a significant decrease in D band intensity depicts the absence of defects. 
Table 2. Raman intensities for $\mathrm{I}_{\mathrm{D}}, \mathrm{I}_{\mathrm{G}}, \mathrm{I}_{2 \mathrm{D}}, \mathrm{I}_{\mathrm{D}} / \mathrm{I}_{\mathrm{G}}$ and $\mathrm{I}_{2 \mathrm{D}} / \mathrm{I}_{\mathrm{G}}$.

\begin{tabular}{cccccccc}
\hline Sr. no. & Film & \multicolumn{9}{c}{ Intensity (a.u) } & $\mathrm{I}_{\mathrm{D}} / \mathrm{I}$ & $\mathrm{I}_{2 \mathrm{D}} / \mathrm{I}_{\mathrm{G}}$ & Remarks \\
& & $\mathrm{I}_{\mathrm{D}}$ & $\mathrm{I}_{\mathrm{G}}$ & $\mathrm{I}_{2 \mathrm{D}}$ & & & \\
\hline \hline 1 & $\mathrm{Ni}-3500$ & 650 & 747 & 40 & 0.85 & 0.05 & no graphene formation \\
2 & $\mathrm{Ni}-4500$ & 157 & 104 & 104 & 1.5 & 1 & bi-layer graphene \\
3 & $\mathrm{Ni}-5500$ & 70 & 54 & 30 & 1.29 & 0.55 & 5 layer graphene \\
4 & $\mathrm{Ni}-6500$ & 130 & 112 & 65 & 1.16 & 0.58 & 4 layer graphene \\
5 & $\mathrm{Ni}-7500$ & 3179 & 5071 & 3115 & 0.62 & 0.65 & tri-layer graphene \\
\hline
\end{tabular}

Changes in D, G and 2D peak positions in all films corresponding to different number of laser shots on $\mathrm{Ni}$ are illustrated in Table 3. In the case of $\mathrm{Ni}-7500$, there is a shift in the $\mathrm{D}, \mathrm{G}$ and $2 \mathrm{D}$ peak positions towards the lower wave numbers. A downward shift in 2D, D and G peak positions is also observed in the case of Ni-6500, Ni-5500 and Ni-4500, respectively. This downward shift is called red shift and is due to phonon softening, which is caused by tensile strain experienced by the layered structure [27]. Upward shift in D peak position of the film Ni-4500 and the shift in 2D peak positions of Ni-5500 and Ni-4500 towards the higher wave numbers are due to thermal stress, and they occur due to substrate heating. As a result of compressive stress, blue shifted 2D peak, due to phonon hardening, is observed in the Raman spectra [28].

In the case of Ni-3500 (Fig. 2a) the ratio $\mathrm{I}_{2 \mathrm{D}} / \mathrm{I}_{\mathrm{G}}$ is 0.05 . Table 2 shows that there is no evidence of graphene formation. It means that 3500 number of laser shots on $\mathrm{Ni}$ is insufficient for the growth of graphene. The reason is that during laser ablation of the $\mathrm{C}$ target, the ejected $\mathrm{C}$ atoms are deposited on and adsorbed by the Ni layer. During substrate cooling, the amount of $\mathrm{C}$ segregated from $\mathrm{Ni}$ depends on the initial saturation status of $\mathrm{C}-\mathrm{Ni}$ solid solution. For a fixed amount of $\mathrm{C}$ deposited onto the Ni films at $530{ }^{\circ} \mathrm{C}$ substrate temperature, $\mathrm{C}$ saturation in $\mathrm{C}-\mathrm{Ni}$ solid solution is easier to reach the thinnest Ni film (Ni-3500). It results in the smallest $\mathrm{Ni}$ volume. Therefore, in this case, the sample reaches $\mathrm{C}$ supersaturation easily. When it is cooled to room temperature, the solubility of $\mathrm{Ni}$ becomes weak. Consequently, less carbon is required to form a solid solution with $\mathrm{Ni}$ films. The reduction of the solubility of Ni leads to C precipitation [29]. For the deposited film Ni-4500, $\mathrm{I}_{2 \mathrm{D}} / \mathrm{I}_{\mathrm{G}}=1$, which gives the indication of bi-layer graphene [30]. The intensity of $G$ peak increases linearly as the number of graphene layers increases [31]. In the case of films shown in Fig. 2 (c-e), the intensity ratios $\mathrm{I}_{2 \mathrm{D}} / \mathrm{I}_{\mathrm{G}}$ are more than $50 \%$, implying the formation of bi-, triand few-layer graphene [22].

In case of the film Ni-7500, the Raman spectrum (Fig. 2e) has a particular shape of 2D band, FWHM greater than $60 \mathrm{~cm}^{-1}$ and $\mathrm{I}_{2 \mathrm{D}} / \mathrm{I}_{\mathrm{G}}$ value $<1$, which all reveal the fact of existence of trilayer graphene. The film Ni-7500 also appears as the best film among all the deposited films, showing fewer defects (smallest $I_{D} / I_{G}$ value) [32].

\subsection{AFM analysis}

AFM micrographs of the deposited films provide the detailed information about the surface morphology and the height of few-layer graphene by line profile. AFM in tapping mode has been used to characterize the samples.

Left column of Fig. 3 represents the 2D AFM micrographs of graphene deposited at different laser shots on $\mathrm{Ni}$, keeping 200 laser shots on graphite constant for all deposition processes. Central column in Fig. 3 represents the corresponding line profile of the contrast image drawn at the intersection of layers along the lines indicated in the micrographs. Right column in Fig. 3 presents the 2D AFM micrographs after convolution process showing much clear, layer by layer, the growth of graphene.

The number of graphene layers can be identified by color contrast of images. The number of graphene layers can also be calculated 
Table 3. Changes in D, G and 2D peak positions for different laser shots on Ni.

\begin{tabular}{ccccc}
\hline Film & Laser shots on Ni & D peak position & G peak position & 2D peak position \\
\hline \hline Ni-3500 & 3500 & 1332 & 1600 & 2678 \\
Ni-4500 & 4500 & 1334 & 1596 & 2680 \\
Ni-5500 & 5500 & 1330 & 1600 & 2695 \\
Ni-6500 & 6500 & 1332 & 1600 & 2635 \\
Ni-7500 & 7500 & 1327 & 1571 & 2666 \\
\hline
\end{tabular}

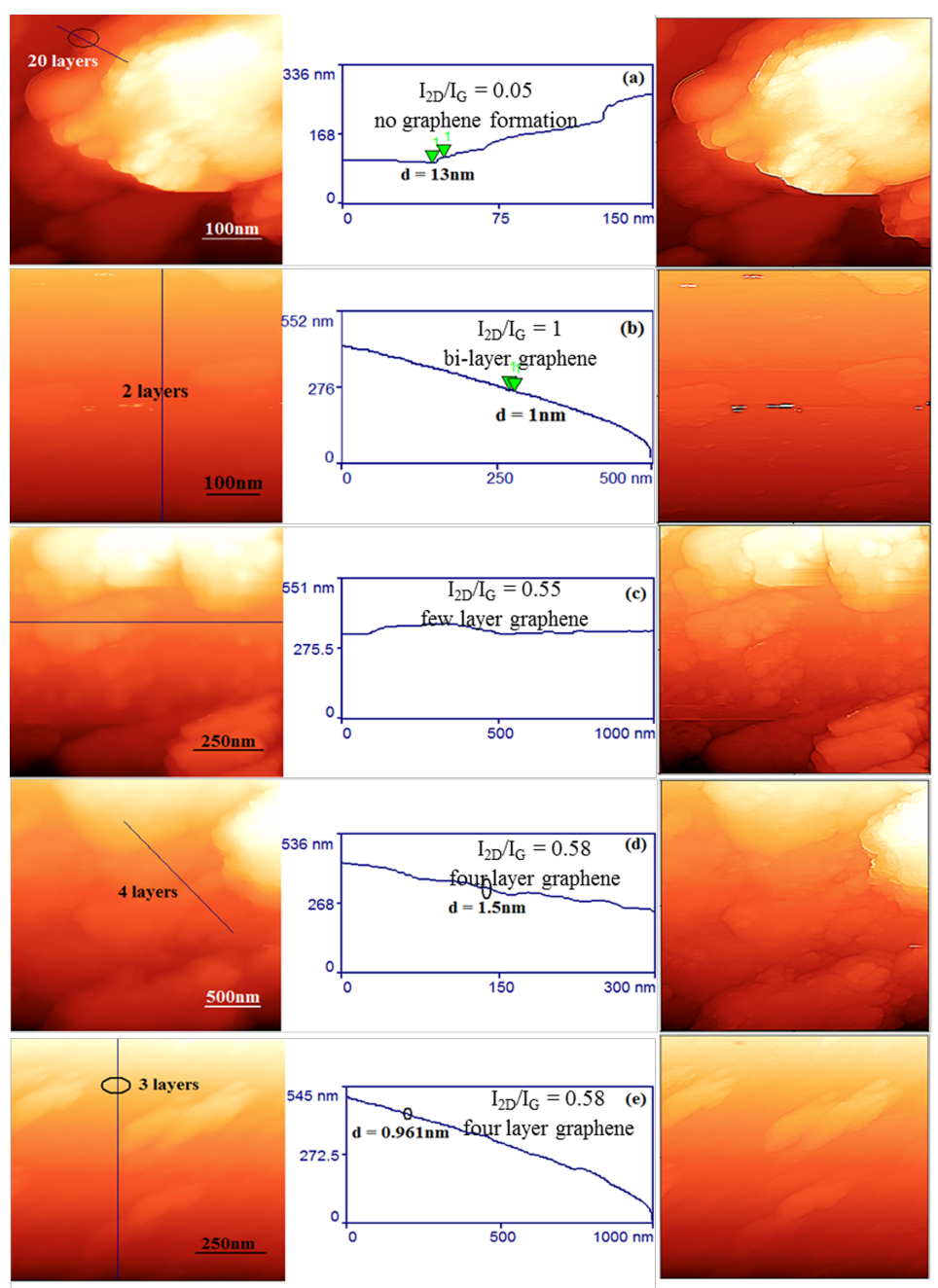

Fig. 3. AFM micrographs and line profiles of graphene prepared with different Ni concentration which was varied by using (a) 3500, (b) 4500, (c) 5500, (d) 6500 and (e) 7500 laser shots on Ni.

by using the formula $\mathrm{d}_{1}=\mathrm{n} \times \Delta \mathrm{d}$, where $\mathrm{d}_{1}$ is the height of graphene layers, $\mathrm{n}$ is the number of layers and $\Delta \mathrm{d}$ is the theoretically measured value of interlayer spacing between two graphene layers, which is $0.335 \mathrm{~nm}$ [33].
The number of graphene layers equal to 38 , calculated for the encircled region (thickness $13 \mathrm{~nm}$ ) in the line profile of the AFM micrograph of Ni-3500 (Fig. 3a), gives a clear indication that there is no evidence of mono-, bi- or tri-layer 
graphene formation. This result has also been verified by Raman spectra of the film Ni-3500. Bilayer graphene is indicative in the region of $1 \mathrm{~nm}$ thickness, occurring in the line profile of Ni-4500 and $\mathrm{Ni}-5500$.

The line profile of the sample Ni-6500 shown in Fig. $3 \mathrm{~d}$ represents slight increase in graphene layers thickness $(\mathrm{d}=1.5 \mathrm{~nm})$ indicating 3 or 4 layers graphene formation [22].

For the film Ni-7500, the height profile across the vertical line marked on the AFM micrograph of Fig. 3e shows that the thickness of this graphene sample ranges from $0.9 \mathrm{~nm}$ to $1.2 \mathrm{~nm}$, suggesting three graphene layers.

\section{Conclusions}

Optimized conditions for growing bi-, tri- and few layer graphene fabricated on $\mathrm{Ni}$ thin films were achieved by pulsed laser deposition technique. The growth conditions for Ni-7500 are the best to achieve low defect tri-layer graphene. 4500 number of laser shots on $\mathrm{Ni}$ has been proved as the best minimal $\mathrm{Ni}$ concentration to grow bilayer graphene. Film Ni-3500 provides no indication of graphene growth due to nonuniform Ni matrix unable to grow graphene. It is concluded that graphene growth is sensitive to $\mathrm{Ni}$ film uniformity and concentration.

\section{References}

[1] Wallace P.R., Phys. Rev., 71 (1947), 622.

[2] Novoselov K.S., Geim A.K., Morozov S.V., JiAng D., Zhang Y., Dubonos V., Science, 306 (2004), 666.

[3] Geim A.K., Novoselov K.S., Nat. Mater., 6 (2007), 183.

[4] Dychalska A., Popielarski P., Frankow W., FAbisiak K., Paprocki K., Szybowicz M., Mater. Sci-Poland, 33 (2015), 799.

[5] Meric I., Han M.Y., Young A.F., Ozyilmaz B., KIM P., ShePARD K.L., Nat. Nanotechnol., 3 (2008), 654.

[6] Hamilton J.C., Blakely J.M., Surf. Sci., 91 (1980), 199.

[7] Lyon H.B., Somorjai G.A., J. Chem. Phys., 46 (1967), 2539.
[8] Zheng M., TAKei K., Hsia B., FAng H., Zhang X., Ferralis N., Ko H., Chueh Y.L., Zhang Y., Maboudian R., Javey A., Appl. Phys. Lett., 96 (2010), 063110.

[9] Nast O., Puzzer T., Koschier L.M., Sproul A.B., Wenham S.R., Appl. Phys. Lett., 73 (1998), 3214.

[10] Tan Z., Heald S.M., Rapposch M., Bouldin C.E., Woicik J.C., Phys. Rev. B, 46 (1992), 9505.

[11] Li X., Cai W., An J., Kim S., NaH J., Yang D., Piner R., Velamakanni A., Jung I., Tutuc E., BANerJeE S.K., Colombo L., RuOfF R.S., Science, 324 (2009), 1312.

[12] Reina A., Jia X., Ho J., Nezich D., Son H., Bulovic V., Dresselhaus M.S., Kong J., Nano Lett., 9 (2009), 3087.

[13] Zarotti F., Gupta B., Iacopi F., Sgarlata A., Tomellini M., Motta N., Carbon, 98 (2016), 307.

[14] Cho S.Y., Kim H.M., LeE M.H., LeE D.J., Kim K.B., Curr. Appl. Phys., 12 (2012), 1088.

[15] Edwards R.S., Coleman K.S., Accounts Chem. Res., 46 (2013), 23.

[16] Stankovich S., Dikin D.A., Piner R.D., KohlhaAs K.A., Kleinhammes A., JiA Y., Wu Y., NguYen S.T., Ruoff R.S., Carbon, 45 (2007), 1558.

[17] Moreau E., Ferrer F.J., Vignaud D., Godey S., Wallart X., Phys. Status Solidi A, 207 (2010), 300.

[18] Ahmadi S., Afzalzadeh R., Physica E, 81 (2016), 302.

[19] Tite T., Donnet C., Loir A.-S., Reynaud S., Michalon J.-Y., Vocanson F., Garrelie F., Appl. Phys. Lett., 104 (2014), 041912.

[20] Koh A.T.T., Foong Y.M., ChuA D.H.C., Diam. Relat, Mater., 25 (2012), 98.

[21] Kumar I., Khare A., Appl. Surf. Sci., 317 (2014), 1004.

[22] Wang K., Tai G., Wong K.H., LaU S.P., GuO W., AIP. Adv., 1 (2011), 022141.

[23] Ferrari A.C., Robertson J., Phys. Rev. B, 64 (2001), 075414.

[24] Tuinstra F., Koenig J.L., J. Chem. Phys., 53 (1970), 1126.

[25] Ferrari A.C., Solid State Commun., 143 (2007), 47.

[26] Ferrari A.C., Meyer J.C., Scardaci V., Casiraghi C., Lazzeri M., Mauri F., Piscanec S., Jiang D., Novoselov K.S., Roth S., Geim A.K., Phys. Rev. Lett., 97 (2006), 187401.

[27] Huang M., Yan H., Heinz T.F., Hone J., Nano Lett., 10 (2010), 4074.

[28] Ferralis N., J. Mater. Sci., 45 (2010), 5135.

[29] Wintterlin J., Bocquet M.L., Surf. Sci., 603 (2009), 1841.

[30] Lu Y., Merchant C.A., Drndi M., Johnson A.T.C., Nano Lett., 11 (2011), 5184.

[31] WANG Y.Y., Ni Z.H., YU T., Shen Z.X., WANG H.M., Wu Y.H., Chen W., WeE A.T.S., J. Phys. Chem. C, 112 (2008), 10637. 
[32] Seunghyun L., Kyunghoon L., Zhaohui Z., Nano Lett., 10 (2010), 4702.

[33] Ni Z.H., Wang H.M., Kasim J., FAn H.M., Yu T., Wu Y.H., Feng Y.P., Shen Z.X., Nano Lett., 7 (2007), 2758.

Received 2016-01-24

Accepted 2017-11-18 